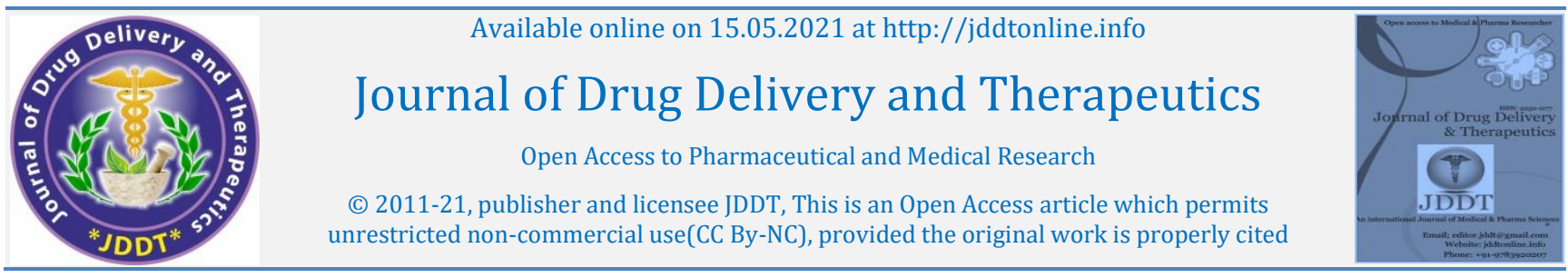

(C) 2011-21, publisher and licensee JDDT, This is an Open Access article which permits

Open Access Full Text Article

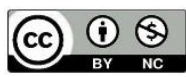

Research Article

\title{
Hemodialysis and hemodiafiltration-induced transient hypercalcemia: an unrecognized phenomenon with potential for calcium-loss and vascular calcification
}

\author{
Kamel El-Reshaid *, Shaikha Al-Bader **, Salah El-Marzabani ***, Ehab Ahmad ** \\ * Department of Medicine, Faculty of Medicine, Kuwait University, Kuwait \\ ** Department of Medicine, Nephrology unit, Amiri hospital, Ministry of health, Kuwait \\ *** Edelia dialysis center, Ministry of health, Kuwait
}

Article Info:

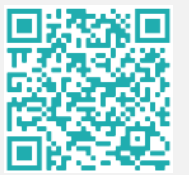

\section{Article History:}

Received 26 March 2021

Review Completed 28 April 2021

Accepted 05 May 2021

Available online 15 May 2021

Cite this article as:

El-Reshaid K, Al-Bader S, El-Marzabani S, Ahmad E, Hemodialysis and hemodiafiltration-induced transient hypercalcemia: an unrecognized phenomenon with potential for calcium-loss and vascular calcification, Journal of Drug Delivery and Therapeutics. 2021: 11(3):58-60

DOI: http://dx.doi.org/10.22270/jddt.v11i3.4779

\section{Abstract}

Uremic vascular calcification is prevalent in $70-80 \%$ of end-stage kidney disease (ESRD) patients and is an independent predictor of cardiovascular morbidity and mortality. In this study we report our experience with significant transient hypercalcemia during maintenance hemodialysis (HD) in 105 patients and hemodiafiltration (HDF) in another 44 ones. The studied patients had controlled predialysis levels of calcium, phosphorus, 1 , 25 vitamin $\mathrm{D}$ and parathyroid hormone. Treatment was associated with high dialysate calcium and low serum phosphorus without significant changes in parathyroid hormone levels. Pre-treatment with a single dose of Fosamax; resulted in amelioration of hypercalcemia indicating its bone etiology. In conclusion; maintenance HD and HDF are associated with inherent hypercalcemia which may contribute to osteomalacia and uremic vascular calcification in ESRD patients.

Keywords: Bisphosphonates, HD, HDF, hypercalcemia, hypophosphatemia, osteomalacia, vascular calcification, uremia.

*Address for Correspondence: Kamel El-Reshaid, Department of Medicine, Faculty of Medicine, Kuwait University, Kuwait

\section{INTRODUCTION}

Uremic vascular calcification (VC) was first reported more than 100 years ago 1 . Subsequently, such association was confirmed in autopsy studies between 1855 and $1945^{2}$. VC is common in patients with end-stage kidney disease (ESRD) with a prevalence of $70 \%-80 \% \quad 3$. The adjusted cardiovascular mortality, in this patient population, is 10 to 20 times higher than in the general population and multiple studies have demonstrated that VC is an independent predictor of cardiovascular morbidity and mortality 4 . VC occurs in two distinct sites, the intimal and medial layers. Intimal calcification is associated with atherosclerotic stenotic plaques and medial calcification with vascular stiffening and peripheral ischemia 5 . Though both forms of calcification can develop in renal patients; medial one is more common ${ }^{2}$. Traditionally, $\mathrm{VC}$ was considered a passive process associated with advanced age, atherosclerosis, uncommon genetic diseases and some metabolic alterations such as diabetes mellitus and ESRD. However, recent studies have disclosed cellular inflammation induced by VC, in genetically predisposed individuals, leading to transformation of vascular smooth muscle cells (VSMC) into ostechondrogenic ones ${ }^{6}$. The mechanisms of such vascular calcification include: (a) genetic predisposition to deposition of bioapatite crystals in VSMC following oversaturation with calcium (Ca) 7, 8, (b) uremic injury to the matrix vesicles of VSMC, by bioapatite deposition, leading to local apoptosis 9 , (c) loss of inhibitors of calcification by uremia viz. matrix GLa protein, fetuin A, osteopontin, osteoprotegerin $\mathbf{1 0}$, and finally (d) induction of uremic calcification-activators leading to transformation of VSMC to osteoblasts viz. TNF, 25 hydroxycholesterol, cytokines, fibronectin 11. Hence, efforts aimed at limiting uremic VC may improve survival in patients' population. This study was conducted to assess a potential role of 2 common blood purification therapy (BPT) viz. maintenance hemodialysis (HD) and hemodiafiltration (HDF) in induction of hypercalcemia and the benefit of bisphosphonate in stabilizing this phenomenon.

\section{PATIENTS AND METHODS}

The study was conducted at Edelia dialysis unit. The latter is the main satellite dialysis unit for the capital area of Kuwait city. It has adequate laboratory diagnostic as well as therapeutic facilities to care for ESRD patients with different modalities of dialysis. Patients were included in the study if they were; (a) adults, (b) with efficient hemodialysis access, (c) with stable cardiovascular status, (d) compliant with both medical and BPT for a minimum of 12 months. Stable cardiovascular status included lack of recent sepsis, peptic ulceration, cardiovascular event, chronic debilitating disease and tumors. All patients were compliant to diet restricted in protein and phosphorus and on regular treatment with Calcium carbonate, One alpha and Sevelamer carbonate for 
their renal osteodystrophy. All had normal levels of 1, 25 dihydroxyvitamin D.

HD technique:

Using Gambro 200 Ultra S machines; sessions were done for 4 hours 3 times/week using cuprophan low-flux hemofilters with ultrafiltration coefficient at $5.5 \mathrm{ml} /$ hour $/ \mathrm{mmHg}$. Blood and dialysate flow rates were $200 \mathrm{ml} / \mathrm{min}$ and $350 \mathrm{ml} / \mathrm{min}$, respectively.

\section{HDF technique:}

Using Fresenius 5008 machines; sessions were done for 4 hours 3 times/week using Nephral 400 ST high-flux filters (AN69 ST membrane with ultrafiltration coefficient at 50 $\mathrm{ml} /$ hour/mmHg). Blood speed was set at $200 \mathrm{ml} /$ minute and dialysate flow at $500 \mathrm{ml} /$ minute.

Initial assessment:

Included laboratory testing for corrected serum $\mathrm{Ca}$, ionized Ca (iCa), P, bicarbonate (HCO) before starting BPT (time 0) then at the end of the session 4 hours later (time 4) then 4 hours after termination of BPT session (time 8). Intact parathyroid hormone (PTH) was tested at time 0 and time 8. From the previous results; CaXP was calculated at times 0,4 and 8 hours.

\section{Subsequent testing:}

All patients had received 1 tablet of Fosamax (Alendronate sodium) $70 \mathrm{mg}$ at early morning on empty stomach and with $1 / 2$ cup of water before and after. For $1 / 2$ hour; patients were instructed to avoid lying down. Subsequently, patients had BPT every other day X 3 and on the $6^{\text {th }}$ day ( $3^{\text {rd }}$ hemodialysis session); all the initial tests and calculations were repeated.

\section{Statistical analysis:}

SPSS statistical package version 25 was used for data entry and processing. The $p$-value $\leq 0.05$ was used as the cut-off level for significance. Since the age, duration of prior hemodialysis were not normally distributed; the median and (Interquartile Range) were used to express the groups. Mann-Whitney U test was used to compare groups of gender and type of renal disease while Wilcoxon Signed Rank test was to compare laboratory data prior Fosamax therapy with that subsequent to it.

\section{RESULTS}

Two groups of patients were studied viz. those on maintenance HD and HDF.

\section{Demographical data:}

In the HD group a total of 105 patients were included. Their age was 50(9) years. In this group; males were 52 (49.5\%), diabetics $57(54.3 \%)$ and they had received maintenance therapy for 23(10) months. In the HDF group a total of 44 patients were included. Their age was 51(6) years. In this group; males were 22 (50\%), diabetics 23 (52.3\%) and they had received maintenance therapy for $17(4)$ months.

Changes in serum electrolytes during HD and HDF:

Serum electrolytes and PTH levels at (4 hours and 8 hours) are summarized in Table 1 . Levels of (serum $\mathrm{Ca}, \mathrm{iCa}, \mathrm{HCO}$ ) had increased and levels of (serum P, CaXP) had decreased by 4 hours then, by 8 hours, such changes were less but did not reach their starting levels $(\mathrm{p}<0.001)$. PTH levels did not change significantly. Pretreatment with Fosamax resulted in milder changes yet not in $\mathrm{P}$ levels. The results were not different with respect to gender and type of renal disease.

Table 1: Electrolytes changes during hemodialysis and hemodiafilteration before and after Fosamax treatment.

\begin{tabular}{|c|c|c|c|c|c|}
\hline \multicolumn{6}{|l|}{ Hemodialysis group $(n=105)$ : } \\
\hline & \multicolumn{2}{|c|}{ A- Before Fosamax: } & \multicolumn{3}{|c|}{ B- After Fosamax: } \\
\hline $\mathrm{Ca} 0$ & $\mathrm{Ca} 4$ & Ca 8 & $\mathrm{Ca} 0$ & $\mathrm{Ca} 4$ & $\mathrm{Ca} 8$ \\
\hline$\overline{2.3(0.1)}$ & $\overline{2.7(0.2)}$ & $2.5(0.1)$ & $2.3(0.1)$ & $2.6(0.2)$ & $\overline{2.4(0.2)}$ \\
\hline $\mathrm{iCa} 0$ & $\mathrm{iCa} 4$ & iCa 8 & iCa 0 & $\mathrm{iCa} 4$ & iCa 8 \\
\hline$\overline{1.15(0.05)}$ & $\overline{1.35(0.1)}$ & $\overline{1.25(0.05)}$ & $\overline{1.15(0.05)}$ & $\overline{1.3(0.08)}$ & $\overline{1.2(0.1)}$ \\
\hline $\mathrm{P} 0$ & P 4 & P 8 & P 0 & P 4 & P 8 \\
\hline $1.6(0.5)$ & $1(0.4)$ & $1.3(0.4)$ & $1.6(0.5)$ & $1(0.4)$ & $\overline{1.2(0.3)}$ \\
\hline Са X P 0 & $\mathrm{Ca} \times \mathrm{P} 4$ & $\mathrm{Ca}$ X P 8 & Са X P 0 & $\mathrm{Ca} \times \mathrm{P} 4$ & Сa X P 8 \\
\hline$\overline{3.5(1.24)}$ & $\overline{2.8(0.98)}$ & $3.2(1.1)$ & $3.5(1)$ & $2.6(1)$ & $3(0.6)$ \\
\hline $\mathrm{HCO} 0$ & $\mathrm{HCO} 4$ & $\mathrm{HCO} 8$ & $\mathrm{HCO} 0$ & $\mathrm{HCO} 4$ & $\mathrm{HCO} 8$ \\
\hline $18(2)$ & $27(2)$ & $26(1)$ & $18(3)$ & $27(2)$ & $26(1)$ \\
\hline PTH: & & PTH: & PTH: & & PTH: \\
\hline$\overline{28(4)}$ & & $\overline{28(3)}$ & $\overline{28(5)}$ & & $\overline{28(4)}$ \\
\hline \multicolumn{6}{|c|}{ Hemodiafilteration group $(n=44)$ : } \\
\hline & \multicolumn{2}{|c|}{ A- Before Fosamax: } & \multicolumn{3}{|c|}{ B- After Fosamax: } \\
\hline $\mathrm{Ca} 0$ & Ca 4 & Ca 8 & $\mathrm{Ca} 0$ & $\mathrm{Ca} 4$ & Ca 8 \\
\hline $2.3(0.1)$ & $2.6(0.1)$ & $2.5(0.1)$ & $2.3(0.1)$ & $2.5(0.1)$ & $\overline{2.4(0.1)}$ \\
\hline $\mathrm{iCa} 0$ & $\mathrm{iCa} 4$ & iCa 8 & $\mathrm{iCa} 0$ & $\mathrm{iCa} 4$ & iCa 8 \\
\hline$\overline{1.2(0.05)}$ & $\overline{1.3(0.05)}$ & $\overline{1.25(0.05)}$ & $\overline{1.2(0.05)}$ & $\overline{1.25(0.05)}$ & $\overline{1.2(0.05)}$ \\
\hline P 0 & P 4 & P 8 & P 0 & P 4 & P 8 \\
\hline $1.5(0.1)$ & $0.8(0.2)$ & $1.1(0.1)$ & $1.5(0.2)$ & $0.8(0.2)$ & $\overline{1.2(0.1)}$ \\
\hline Сa X P 0 & Сa XP 4 & $\mathrm{Ca}$ X $\mathrm{P} 8$ & Сa X P 0 & $\mathrm{Ca} \times \mathrm{P} 4$ & Ca X P 8 \\
\hline$\overline{3.5(0.4)}$ & $\overline{2.2(0.5)}$ & $2.8(0.4)$ & $\overline{3.5(0.3)}$ & $2(0.5)$ & $\overline{2.8(0.4)}$ \\
\hline $\mathrm{HCO} 0$ & $\mathrm{HCO} 4$ & $\mathrm{HCO} 8$ & $\mathrm{HCO} 0$ & $\mathrm{HCO} 4$ & $\mathrm{HCO} 8$ \\
\hline $18(1)$ & $26(2)$ & $25(2)$ & $18(1)$ & $26(1)$ & $25(1)$ \\
\hline PTH: & & PTH: & PTH: & & PTH: \\
\hline$\overline{26(2)}$ & & $\overline{26(3)}$ & $\overline{26(5)}$ & & $\overline{26(4)}$ \\
\hline
\end{tabular}


Changes in composition of electrolytes in dialysate fluid during $H D$ and $H D F$ :

The changes in $\mathrm{iCa}, \mathrm{P}$ and HCO at start of therapy and by 4 hours are summarized in Table 2. As expected; P content had increased significantly yet iCa had increased also. Again; changes were less after pretreatment with Fosamax and were not different with respect to gender and type of renal disease.

Table 2: Changes in dialysate electrolytes before and after Fosamax therapy

A- Hemodialysis group $(n=105)$ :

\begin{tabular}{|c|c|c|c|}
\hline \multicolumn{2}{|c|}{ Before Fosamax } & \multicolumn{2}{|c|}{ After Fosamax } \\
\hline iCa 0 & iCa4 & iCa 0 & iCa4 \\
\hline 1.75 & $1.82(0.1)$ & 1.75 & $1.75(0.4)$ \\
\hline $\mathrm{P} 0$ & $\mathrm{P} 4$ & P 0 & $\mathrm{P} 4$ \\
\hline 0 & $0.6(0.2)$ & 0 & $0.5(0.4)$ \\
\hline $\mathrm{HCO} 0$ & $\underline{\mathrm{HCO} 4}$ & $\mathrm{HCO} 0$ & $\underline{\mathrm{HCO} 4}$ \\
\hline 32 & $27(2)$ & 32 & $27(2)$ \\
\hline
\end{tabular}

B- Hemodialfilteration group $(n=44)$ : Before Fosamax

\begin{tabular}{|c|c|}
\hline $\mathrm{iCa} 0$ & iCa4 \\
\hline 1.75 & $1.8(0.8)$ \\
\hline P 0 & P 4 \\
\hline 0 & $0.4(0.4)$ \\
\hline $\mathrm{HCO} 0$ & $\underline{\mathrm{HCO}} 4$ \\
\hline 8 & \\
\hline
\end{tabular}

\begin{tabular}{|c|c|}
\hline \multicolumn{2}{|c|}{ After Fosamax } \\
\hline iCa 0 & iCa4 \\
\hline 1.7 & $1.7(0.6)$ \\
\hline P 0 & P 4 \\
\hline 0 & $0.3(0.2)$ \\
\hline $\mathrm{HCO} 0$ & $\underline{\mathrm{HCO} 4}$ \\
\hline 32 & $26(2)$ \\
\hline
\end{tabular}

Abbreviations: ionized calcium (iCa), phosphorus (P), bicarbonate (HCO).

Time of testing with regards dialytic therapy: at start (0), 4 hours later (4), 8 hours later (8)

\section{DISCUSSION}

In our study, hypercalcemia developed during the 4 hours of both BPT then decrease subsequently yet remained significantly high 4 hours later. During BPT, serum Ca level was more than that in the initial dialysate fluid. Moreover, it's concentration in the final dialysate was higher than that in the dialysate bags indicating Ca leak in dialysate during BPT. The only plausible source for such hypercalcemia is the patients' bones. Confirmation of our theory came with repeating the investigations after treatment with Fosamax in an attempt to decrease the osteoclastic activity. After a single tablet of it; previous hypercalcemia was ameliorated. Unfortunately, Bisphosphonate therapy is not recommended, in patients with GFR $<30 \%$, since renally excreted with potential risk for adynamic bone disease $\mathbf{1 2}$. However, some researchers have used Bisphosphonates successfully, at lower doses, to prevent hip fractures in this patient population 13. Moreover, Bisphosphonates have been shown to reduce vascular calcification via inhibition of the expression of TNF- $\alpha$, which promotes osteoblastic differentiation, as well as calcium deposition in atheromatous lesions of rabbit aorta 14. The stimulus for bone resorption is intriguing yet is BPT-induced hypophosphatemia was the only plausible culprit. A recent study has shown an association between post-dialysis hypophosphatemia and low bone mineral density in chronic dialysis patients $\mathbf{1 5}$.

In conclusion: significant transient hypercalcemia has been observed during BPT and is associated with Ca loss in the dialysate fluid. Measures to assess and correct its long-term sequelae on vascular calcification and renal osteodystrophy are indicated.

\section{REFERENCES:}

1- Bryant JH, Hale-White W. A case of calcification of the arteries and obliterative endarteritis, associated with hydronephrosis, in a child aged six months. Guys Hosp Rep 1901; 40:17-28.

2- Mulligan, RM. Metastatic calcification. Arch Pathol 1946; 42:177-230.

3- Blacher J, Guerin AP, Pannier B, Marchais SJ, London GM. Arterial calcifications, arterial stiffness, and cardiovascular risk in end-stage renal disease. Hypertension 2001; 38:938-942.

4- Foley RN, Parfrey PS, Sarnak MJ. Clinical epidemiology of cardiovascular disease in chronic renal disease. Am J Kidney Dis 1998; 32:S112-119.

5- Hunt JL, Fairman R, Mitchell ME, Carpenter JP, Golden M, et al. Bone formation in carotid plaques: a clinicopathological study. Stroke 2002; 33:1214-1219.

6- Giachelli CM. The emerging role of phosphate in vascular calcification. Kidney Int 2009; 75: 890-897.

7- Covic A, Kanabay M, Voroneanu L, Turgut F, Serban DN, et al. Vascular calcification in chronic kidney disease. Clin Sci (London) 2010; 119:111-121.

8- Block GA, Port FK. Re-evaluation of risks associated with hyperphosphatemia and hyperparathyroidism in dialysis patients: Recommendations for a change in management. Am J Kidney Dis 2000; 35:1226-1237.

9- Steitz SA, Speer MY, Curinga G, et al. Smooth muscle cell phenotypic transition associated with calcification: upregulation of Cbfa1 and downregulation of smooth muscle lineage markers. Circ Res 2001; 89:1147-1154.

10- Proudfoot D, Skepper JN, Hegyi L, et al. Apoptosis regulates human vascular calcification in vitro - Evidence for initiation of vascular calcification by apoptotic bodies. Circ Res 2000; 87:1055-62.

11- Valdivielso JM. Vascular calcification: types and mechanisms. Nephrologia 2011; 31:142-147.

12- Bisphosphonates in Chronic Kidney Disease; Balancing Potential Benefits and Adverse Effects on Bone and Soft Tissue. Nigel D. Toussaint, Grahame J. Elder and Peter G. Kerr. CJASN 2009; 4:221-233.

13- Wetmore JB, Benet LZ, Kleinstuck D, Frassetto L: Effects of short-term alendronate on bone mineral density in haemodialysis patients. Nephrology (Carlton) 2005; 10:393399.

14- Ylitalo R, Oksala O, Yla-Herttuala S, Ylitalo P: Effects of clodronate (dichloromethylene bisphosphonate) on the development of experimental atherosclerosis in rabbits. J Lab Clin Med 1994; 123:769-776.

15- Masakane I, Sakai Y, Suzuki E, Suzuki M, Natashima M. FP478Post-dialysis hypophosphatemia might be a risk of losing bone density in chronic dialysis patients? 56 th ERA-EDTA 2019 Congress-Abstracts. 